\title{
Detection of antibodies to tetanus toxoid: comparison of a direct haemagglutination method with a radioimmunoassay
}

\author{
AI SHA WANG*, GF BURNS, IJ KRONBORG, IR MACKAY \\ From the Clinical Research Unit, The Walter and Eliza Hall Institute of Medical Research and the Royal \\ Melbourne Hospital, Melbourne, Victoria, 3050, Australia
}

SUMMARY Two methods of detecting antibodies to tetanus toxoid were compared, a radioimmunoassay (RIA) employing radiolabelled staphylococcal protein A and a direct haemagglutination (HA) method employing sheep erythrocytes coupled to tetanus toxoid with chromic chloride. These were shown to have a similarly high specificity with the HA method showing slightly higher sensitivity. Haemagglutination offers several additional advantages in terms of simplicity, low cost and less requirement for specialised equipment. The assays were also used to demonstrate a transient IgM response after repeated booster injections with absorbed toxin given to seropositive individuals, and these antibodies were found to be protective in biological tests.

Antibodies to tetanus toxin are a reliable indicator of host protection and the measurement of antitetanus immunoglobulin concentrations is of value in assessing the immune status of individuals at risk, in screening potential donors of immune globulin for passive prophylaxis and in monitoring the efficiency of vaccination programs. In areas where prior immunisation with tetanus toxoid is uncertain, testing for antitetanus antibodies remains of vital importance.

Recently, several groups ${ }^{1-3}$ have introduced radioimmunoassays (RIA) for the detection of antitetanus antibodies and, while these appear to be very sensitive and specific, they have generally required purified and radiolabelled antibodies to human immunoglobulins. Moreover, the sensitivity of the RIA test has not been directly correlated with the more common assay of passive haemagglutination (HA) with antigen-coupled tanned red blood cells. ${ }^{4}$

We have adopted an RIA employing radiolabelled staphylococcal protein $A$ in a microtitre system for the detection of antitetanus antibodies and have compared this with a HA method which employs tetanus toxoid coupled to sheep erythrocytes with chromic chloride.

\footnotetext{
Material and methods

SERA

Sera were obtained by venesection from 45 normal

*On sabbatical leave from Capital Hospital, Beijing, Peoples' Republic of China.

Accepted for publication 10 February 1982
}

volunteers within the Institute. All the sera weree decomplemented at $56^{\circ} \mathrm{C}$ and were stored at $-20^{\circ} \mathrm{C}$ until testing. In the immunisation experiments, the volunteers were bled before boosting with tetanus toxoid and then bled again after the time intervals shown in "Results".

\section{TETANUS TOXOID}

For immunisation of the volunteers in the boosting experiments absorbed tetanus toxoid (Commonwealth Serum Laboratories (CSL), Melbourne) obtained in $0.5 \mathrm{ml}$ ampoules was employed. The antigen used for coupling to erythrocytes for the HA test and for addition to the plastic plates for the RIA test was non-absorbed tetanus toxoid (CSL, Melbourne) obtained as 1800 limiting flocculation units (LFU)/ml (2700 LFU/mg of protein nitrogen).

\section{HA TEST}

Sheep erythrocytes (CSL, Melbourne) obtained in Alsever's solution were washed three times in normal saline, with removal of leucocytes after each wash. The cells were then resuspended to $50 \%$ (vol/ vol) in normal saline and coupled to tetanus toxoid with chromic chloride as described previously. ${ }^{56}$ Briefly, to $0.2 \mathrm{ml}$ of the $50 \%$ erythrocytes was added $0.1 \mathrm{ml}$ of $250 \mathrm{LFU} / \mathrm{ml}$ toxoid diluted in normal saline and this mixture was mixed on a vortex mixer. Whilst still on the vortex mixer, $0.5 \mathrm{ml}$ of "aged" chromic chloride $^{5}$ at $0.1 \mathrm{mg} / \mathrm{ml}$ was added dropwise. The coupled cells were then held at room temperature 
for $5 \mathrm{~min}$ and washed twice in normal saline and once in phosphate-buffered saline (PBS) before use. Preliminary experiments employing toxoid at 125 $\mathrm{LFU} / \mathrm{ml}, 250 \mathrm{LFU} / \mathrm{ml}$ and $500 \mathrm{LFU} / \mathrm{ml}$ demonstrated that a slightly higher titre was obtained with $250 \mathrm{LFU} / \mathrm{ml}$ than with $125 \mathrm{LFU} / \mathrm{ml}$, but that no increase in titre was obtained when toxoid was used at $500 \mathrm{LFU} / \mathrm{ml}$. Therefore, toxoid at $250 \mathrm{LFU} / \mathrm{ml}$ was routinely employed for coupling to the erythrocytes. The erythrocytes were resuspended to $5 \%$ (vol/vol) for use in the HA test.

Repeated testing of freshly prepared indicator erythrocytes and coupled erythrocytes which had been held at $4^{\circ} \mathrm{C}$ as a $5 \%$ suspension for up to seven days indicated that the test was very reproducible with different batches of coupled erythrocytes and that these indicator cells could be stored for this time without deterioration.

\section{RIA TEST}

The RIA employed used a method with radiolabelled staphylococcal protein $\mathrm{A}$ as the second layer.? Various preliminary experiments were performed to standardise the quantity of toxoid added to the plastic plate. These assessed the time and temperature employed for binding of antigen to the plates (for example, Fig. 1), how long the antigen-coated plates could be stored at $4^{\circ} \mathrm{C}$, and the optimal time for antibody binding to the coated plates. The results of these experiments were generally clear cut (Fig. 1) and the various conditions were optimised as follows. Each round-bottomed well of the standard microtitre plastic plate (Linbro/Titertek, 76-111-05) received $100 \mu \mathrm{l}$ of toxoid at $2.5 \mathrm{LFU} / \mathrm{ml}$ in distilled water and

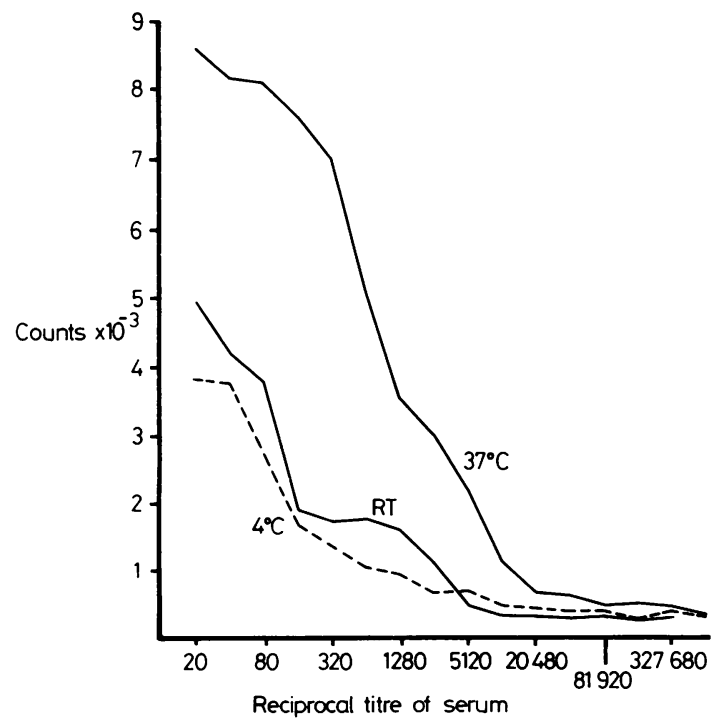

Fig. 1 Tetanus toxoid coated to the plastic plate was optimal at $37^{\circ} \mathrm{C}$ after $2 h$ in the RIA test. the antigen-coated plates could be stored for more than seven days without loss of activity. Coating of antigen to the plastic was optimal after allowing the interaction to take place at $37^{\circ} \mathrm{C}$ (Fig. 1) for $2 \mathrm{~h}$. A plateau of antibody binding to the antigen-coated plate was obtained after $2 \mathrm{~h}$ at room temperature. In every determination a control plate coupled with an unrelated antigen (1\% bovine serum albumin) was included as a non-specific binding control for each serum tested and the final antibody titre was given as the lowest dilution which gave duplicate counts greater than the maximum mean count in the control.

\section{BIOLOGICAL TEST FOR TETANUS ANTITOXIN (BIOASSAY)}

The ability of sera to protect mice from the paralytic effects of a fixed dose of tetanus toxin were compared with a standard preparation of tetanus antitoxin as described in the British Pharmacopoeia. ${ }^{8}$

Table 1 Comparison of HA and RIA titres to tetanus toxoid in 45 normal subjects

\begin{tabular}{|c|c|c|c|}
\hline \multicolumn{2}{|c|}{ Subjects } & $H A$ & $R I A$ \\
\hline $\begin{array}{r}1 \\
2 \\
3 \\
4 \\
5 \\
6 \\
7 \\
8 \\
9 \\
10 \\
11 \\
12 \\
13 \\
14 \\
15 \\
16 \\
17 \\
18 \\
19 \\
20 \\
21 \\
22 \\
23 \\
24 \\
25 \\
26 \\
27 \\
28 \\
29 \\
30 \\
31 \\
32 \\
33 \\
34 \\
35 \\
36 \\
37 \\
38 \\
39 \\
40 \\
41 \\
42 \\
43 \\
44 \\
45\end{array}$ & 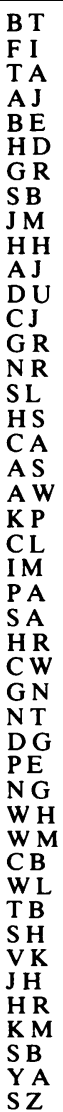 & $\begin{array}{l}1 / 2560 \\
1 / 655360 \\
1 / 40960 \\
1 / 20480 \\
1 / 655360 \\
1 / 40960 \\
1 / 655360 \\
1 / 81920 \\
1 / 40960 \\
1 / 640 \\
1 / 20480 \\
1 / 40960 \\
1 / 81920 \\
1 / 163840 \\
1 / 40960 \\
1 / 5120 \\
1 / 20480 \\
1 / 20 \\
1 / 10240 \\
1 / 640 \\
1 / 40960 \\
1 / 2560 \\
1 / 20 \\
1 / 40960 \\
1 / 20 \\
1 / 20480 \\
1 / 81920 \\
1 / 20480 \\
1 / 20480 \\
1 / 40960 \\
1 / 160 \\
1 / 320 \\
1 / 10240 \\
1 / 640 \\
1 / 640 \\
1 / 20480 \\
1 / 40960 \\
1 / 80 \\
1 / 2560 \\
1 / 40 \\
1 / 81920 \\
1 / 40960 \\
1 / 81920 \\
1 / 20480 \\
1 / 640\end{array}$ & $\begin{array}{l}1 / 2560 \\
1 / 655360 \\
1 / 20480 \\
1 / 10240 \\
1 / 81920 \\
1 / 10240 \\
1 / 163840 \\
1 / 40960 \\
1 / 10240 \\
1 / 640 \\
1 / 10240 \\
1 / 20480 \\
1 / 20480 \\
1 / 20480 \\
1 / 10240 \\
1 / 1280 \\
1 / 20480 \\
1 / 20 \\
1 / 10240 \\
1 / 320 \\
1 / 5120 \\
1 / 5120 \\
1 / 640 \\
1 / 10240 \\
1 / 320 \\
1 / 10240 \\
1 / 10240 \\
1 / 2560 \\
1 / 2560 \\
1 / 20480 \\
1 / 640 \\
1 / 1280 \\
1 / 2560 \\
1 / 640 \\
1 / 1280 \\
1 / 5120 \\
1 / 5120 \\
1 / 80 \\
1 / 2560 \\
1 / 160 \\
1 / 20480 \\
1 / 10240 \\
1 / 10240 \\
1 / 10240 \\
1 / 320\end{array}$ \\
\hline
\end{tabular}




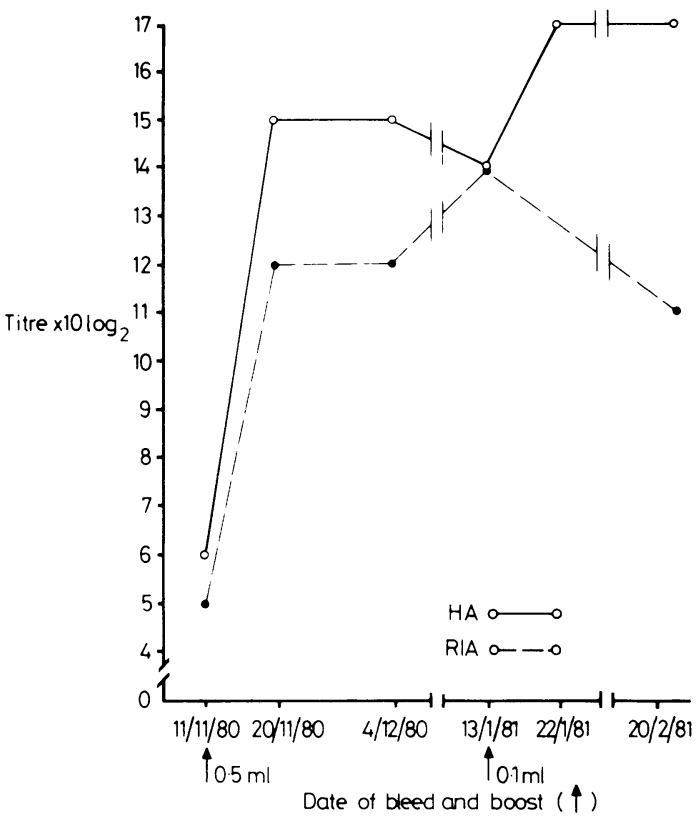

Fig. 2 Comparison of the antitetanus titre by $H A$ and $R I A$ in a subject boosted with tetanus toxoid.

\section{Results}

Serum samples were obtained from 45 normal individuals and the heat-inactivated sera were tested for antitetanus antibody by HA and RIA. The results are presented in Table 1, and it is clear that there was reasonable correlation between the two tests, with the titres from 21 of the samples being identical or within a twofold or less difference in titre. Of the remainder, 19 gave a higher titre when tested by $\mathrm{HA}$, and in only 5 tests was the HA titre lower than the RIA titre. The final endpoint of the HA plates was generally very clear cut and reproducible, and in both tests repeated testing of the sera gave consistent results.

In an experiment three volunteers were boosted with tetanus toxoid and then repeated samples of serum were tested by both HA and RIA. The results from one of these subjects are illustrated in Fig. 2. These tests effectively demonstrated the substantial rise in titre after the booster injections of toxoid, but it was also observed that there was a large discrepancy between the HA and RIA titres in samples immediately after boosting. It was thought that the generally higher titres observed in the HA test might

Table 2 Reduction of HA and RIA titres in sera treated with 2-ME

\begin{tabular}{|c|c|c|c|c|c|}
\hline \multirow[t]{3}{*}{ Subject } & \multirow[t]{3}{*}{ Date of Sample } & \multicolumn{4}{|c|}{ Reciprocal titre } \\
\hline & & \multicolumn{2}{|l|}{$H A$} & \multicolumn{2}{|l|}{$R I A$} \\
\hline & & Untreated & $+2-M E$ & Untreated & $+2-M E$ \\
\hline WA & $\begin{array}{c}11 / 11 / 80)^{*} \\
2(0 / 11 / 80) \\
4 / 12 / 80 \\
13 / 1 / 81^{*} \\
22 / 1 / 81 \\
20 / 2 / 81\end{array}$ & $\begin{array}{r}320 \\
327680 \\
327680 \\
163840 \\
>655360 \\
>655360\end{array}$ & $\begin{array}{r}320 \\
40960 \\
81920 \\
163840 \\
40960 \\
40960\end{array}$ & $\begin{array}{r}320 \\
40960 \\
4096() \\
163840 \\
20480 \\
20480\end{array}$ & $\begin{array}{ll} & 160 \\
1024(0) \\
10 & 240 \\
\text { nd } \\
10) \\
10240 \\
10240\end{array}$ \\
\hline DU & $\begin{array}{l}30 / 10 / 800^{*} \\
11 / 11 / 80\end{array}$ & $\begin{array}{r}320 \\
163840\end{array}$ & $\begin{array}{r}320 \\
20480\end{array}$ & $\begin{array}{r}320 \\
20480\end{array}$ & $\begin{array}{r}160 \\
10240\end{array}$ \\
\hline $\mathrm{ZL}$ & $\begin{array}{c}29 / 11 / 81^{*} \\
8 / 12 / 81\end{array}$ & $\begin{array}{r}640 \\
40960\end{array}$ & $\begin{array}{r}320 \\
5120\end{array}$ & $\begin{array}{r}320 \\
5120\end{array}$ & $\begin{array}{r}320 \\
1280\end{array}$ \\
\hline
\end{tabular}

${ }^{*}$ Booster injection given on this date after serum sample was taken.

Table 3 Correlation of HA titre and the units of mouse protection obtained by bioassay

\begin{tabular}{|c|c|c|c|c|}
\hline \multirow[t]{2}{*}{ Subject } & \multirow[t]{2}{*}{ Date of sample } & \multicolumn{2}{|c|}{ Reciprocal HA titre* } & \multirow{2}{*}{$\begin{array}{l}\text { Bioassay } \\
\text { (units/ml) }\end{array}$} \\
\hline & & Untreated & $+2-M E$ & \\
\hline IW & $\begin{array}{c}11 / 11 / 80 \\
20 / 11 / 80 \\
4 / 12 / 80 \\
13 / 1 / 81\end{array}$ & $\begin{array}{r}320 \\
327680 \\
327680 \\
163840\end{array}$ & $\begin{array}{r}320 \\
40960 \\
81920 \\
163840\end{array}$ & $\begin{array}{r}0 \cdot 32 \\
40 \cdot 96 \\
40 \cdot 96 \\
20 \cdot 48\end{array}$ \\
\hline DU & $\begin{array}{l}30 / 10 / 80 \\
11 / 11 / 80\end{array}$ & $\begin{array}{r}320 \\
163840\end{array}$ & $\begin{array}{r}320 \\
20480\end{array}$ & $\begin{array}{r}0 \cdot 16 \\
20 \cdot 48\end{array}$ \\
\hline
\end{tabular}

*Untreated HA titre measures all antitetanus antibodies including IgM, following 2-ME treatment the titre measures principally IgG antibodies. The bioassay results correlate more closely to the untreated HA titre indicating that IgM antibodies are protective. 
be due to IgM antibody which would not be detected in the RIA using radiolabelled staphylococcal protein A. This was tested for by 2-mercaptoethanol (2-ME) reduction of the IgM followed by a repeated HA test, and the results (Table 2 ) clearly validate this premise. Thus 2-ME treatment of the samples reduced the very high HA titres to within one well of the RIA titre whereas the same treatment had no effect on the preimmunisation samples or on the samples taken some eight weeks after boosting. The slight reduction of one to two wells seen in the RIA results after treatment with 2-ME may demonstrate that some IgM was binding the radiolabelled protein A used in this assay, but a one well reduction was also seen in two of the preimmunisation bleeds suggesting a slight non-specific effect of 2-ME. We investigated whether IgM antibodies were likely to be protective in vivo by means of mouse protection tests and the results (Table 3 ) were that the HA titre correlated with the units of protection in the bioassay. This was true whether the major component of the antibody was IgM or IgG.

\section{Discussion}

Both of the methods described in this paper, HA and RIA, are demonstrated to be very sensitive for the detection of antitetanus toxoid IgG antibodies. The level of sensitivity was such that at the highest dilutions we were detecting the specific antibody contained in about $0.0023 \mu \mathrm{g}$ of IgG. The methods were also highly specific. In the RIA, our routine control was an unrelated antigen (bovine serum albumin) coated to the plate, but we also found that normal rabbit serum, which strongly binds protein $\mathrm{A}$, added to the plates coated with tetanus toxoid gave very low background counts. In the HA test, sheep erythrocytes which had not been coupled to tetanus toxoid revealed low levels of natural antibodies, but since this activity was abolished at $1 / 80$ dilutions of serum, it was not necessary to absorb the sera with erythrocytes prior to testing.

A direct comparison of the RIA and HA showed that of the two methods the HA test appeared to be the more sensitive. The HA test offers further advantages. While the RIA employed in this work was simpler than methods described hitherto with radiolabelled antihuman immunoglobulin, ${ }^{1-3}$ the HA method is simpler to perform, rapid, less expensive in reagents and requires no special equipment such as a gamma counter.

In addition, with the use of $2 \mathrm{ME}$ to reduce IgM antibodies, our experiments with volunteers boosted with tetanus toxoid demonstrated that the HA method was effective in revealing IgM antibodies which are indicative of recent immunisation. These studies also confirm the findings of Hernandez and Burgiss-Wolff ${ }^{\ominus}$ that both primary and secondary vaccination can elicit the formation of transient IgM antibody. Moreover, correlation with mouse protection tests, presumably a more accurate indication of in vivo protection, showed that the high HA values after booster injections which were largely the result of IgM antibodies were reflected by greatly increased mouse protection values.

The assays described in this paper were originally developed in order to screen clones of Epstein-Barr virus transformed B lymphocytes from immunised donors for the production of antitetanus toxoid antibodies. ${ }^{2}$ Such human antibodies produced in vitro may eventually prove of great value for passive protection against tetanus. The rapidity and simplicity of the HA method described here make this an ideal procedure for the detection of clones secreting antibody to tetanus toxoid in vitro.

We thank Dr John Hurrell of the Commonwealth Serum Laboratories, Melbourne, Australia, for carrying out the bioassays. This study was supported in part by the Lions Clubs of Victoria and the National Health and Medical Research Council of Australia.

\section{References}

${ }^{1}$ Repetti CF, Gill TJ. Radioimmunoassay of IgM and IgG antitetanus toxoid antibody. J Immunol Methods 1980;37:153-63.

2 Zurawski VR, Haber E, Black PH. Production of antibody to tetanus toxoid by continuous human lymphoblastoid cell lines. Science 1978;199:1439-41.

3 Stevens RH, Saxon A. Differential synthesis of IgM and IgG antitetanus toxoid antibody in vitro following in vivo booster immunization of humans. Cell Immunol 1979;45:142-50.

4 Barr A, Dow BC, Watson WC, Hunter E. Detection and quantitation of tetanus anti-toxin in blood donations. J Clin Pathol 1975;28:969-71.

${ }^{5}$ Ling NR, Bishop S, Jefferis R. Use of antibody-coated red cells for the sensitive detection of antigen and in rosette tests for cells bearing surface immunoglobulins. J Immunol Methods 1977;15:279-89.

${ }^{6}$ Burns GF, Pike BL. Spontaneous reverse haemolytic plaque formation. I: technical aspects of the protein A assay. J Immunol Methods 1981;41:269-77.

' Salonen E-M, Vaheri A. Immobilization of viral and mycoplasma antigens and of immunoglobulins on polystyrene surface for immunoassays. J Immunol Methods 1979;30:209-18.

- British Pharmacopoeia II. 1980. A133-A134.

- Hernandez RM, Burgiss-Wolff A. Immunoglobulin classes of human anti-toxin after tetanus vaccination studied by immunofluorescence with agarose bound tetanus toxoid. Z ImmunForsch 1973;145:376-84.

Requests for reprints to: Dr IR Mackay, Clinical Research Unit of The Walter and Eliza Hall Institute of Medical Research and the Royal Melbourne Hospital, Post Office, Royal Melbourne Hospital, Victoria 3050, Australia. 